\section{Feedback na educação não formal de português durante a pandemia da COVID-19}

Feedback on non-formal Portuguese education during the COVID-19 pandemic

Kátia Cristina do Amaral TAVARES (UFRJ) katiatavares@letras.ufrj.br

Juliana Pereira GUIMARÃES (UFRJ) juliana@letras.ufrj.br

Recebido em: 31 de jan. de 2021. Aceito em: 25 de ago. de 2021.
TAVARES, Kátia Cristina do Amaral; GUIMARÃES, Juliana Pereira. Feedback na educação não formal de português durante a pandemia da COVID-19. Entrepalavras, Fortaleza, v. 11, n. 3 , e2310, p. 90-113, set.-dez./2021. DOI: $10.22168 / 2237-6321-32310$.

Resumo: Muitos pesquisadores vêm investigando práticas pedagógicas mediadas pelas tecnologias digitais durante a pandemia do novo coronavírus, que trouxe muitos desafios e mudanças para a educação. Nesse contexto, a pesquisa buscou compreender como o feedback opera nas interações entre professora, alunos e conteúdo e na avaliação formativa e subjetiva de uma professora de língua portuguesa que atua na educação não formal durante a pandemia da COVID-19. Situamos a pesquisa no campo da Linguística Aplicada crítica e utilizamos uma abordagem qualitativa de proximidade crítica (MOITA LOPES; FABRICIO, 2019). Analisamos e interpretamos as mensagens trocadas pela professora e os alunos via WhatsApp, como também a avaliação das produções textuais dos alunos e as respostas a um questionário aplicado pela professora. $\mathrm{O}$ estudo se baseou em pressupostos teóricos de ensino e aprendizagem online (ANDERSON, 2003; BONNEL, 2008; LEFFA, 2005; PAIVA, 2003; SIMONSON; SMALDINO; ZVACEK, 2015). Como resultado, constatamos que o feedback integra e potencializa a avaliação e a interação entre professora, alunos e conteúdo, incentivando a colaboração e 
o desenvolvimento de conhecimentos e habilidades sociocomunicativas, culturais, linguísticas e cidadãs. Por fim, concluímos que essas práticas contribuíram para a formação e aprendizagem dos alunos e da professora no ensino remoto.

Palavras-chave: Feedback. Ensino Remoto. Educação não formal.

\begin{abstract}
Many researchers have been investigating pedagogical practices mediated by digital technologies during the pandemic of the new coronavirus that brought many challenges and changes to education. In this context, this research sought to understand how feedback operates in the interactions between teacher, students and content and in the formative and subjective evaluation of a Portuguese language teacher who works in non-formal education during the COVID-19 pandemic. We situate the research in the field of critical Applied Linguistics and use a qualitative approach of critical proximity (MOITA LOPES; FABRÍCIO, 2019). We analyzed and interpreted the messages exchanged by the teacher and the students via WhatsApp, as well as the evaluation of the students' textual productions and the answers to a questionnaire applied by the teacher. The study was based on theoretical assumptions of online teaching and learning (ANDERSON, 2003; BONNEL, 2008; LEFFA, 2005; PAIVA, 2003; SIMONSON; SMALDINO; ZVACEK, 2015). As a result, we found that feedback integrates and enhances the evaluation and interaction between teacher, students and content, encouraging collaboration and the development of sociocommunicative, cultural, linguistic and citizen knowledge and skills. Finally, we conclude that these practices contributed to the training and learning of students and teachers in remote education.
\end{abstract}

Keywords: Feedback. Remote teaching. Non-formal education.

\title{
Introdução
}

As práticas pedagógicas mediadas por tecnologias digitais adotadas durante o ensino remoto emergencial no período da pandemia de COVID-19 têm sido investigadas tanto em contextos de educação formal quanto de educação não formal. A educação não formal tem sido reconhecida como relevante na vida dos cidadãos na contemporaneidade. Gohn (2020) a considera um processo sociocultural e político importante na formação e construção da cidadania das pessoas de diversas classes socioeconômicas, escolaridades, faixas etárias, etnias, nacionalidades etc. A autora defende que devemos olhar para as possibilidades da educação não formal para potencializar a educação formal não como mera complementação, mas como diretriz estruturante.

De acordo com Faustino e Silva (2020), a educação não formal pode favorecer metodologias de ensino-aprendizagem que visam à compreensão, interpretação e resolução de diversas questões por ocorrer fora do sistema comum de ensino, sendo complementar a esse. Nessa perspectiva, a educação não formal consiste em ações educativas organizadas com certa flexibilização nas metodologias e abordagens de ensino, temas e conteúdos, visto que não se inserem no sistema educacional regido por lei e visam facilitar tipos de aprendizagem a grupos específicos (TRILLA, 2008). 
V. 11 (3) 90-113 set-dez 2021
Em março de 2020, o Ministério da Educação (MEC), com resistência às recomendações de isolamento físico da Organização Mundial da Saúde (OMS), autorizou, por meio da Portaria n. 343, de 17 de março de 2020, o Ensino Remoto Emergencial (ERE), que se configura como a substituição das aulas presenciais por aulas que utilizam meios e tecnologias de informação e comunicação enquanto durar a situação de pandemia do novo coronavírus. Inicialmente, o ERE se aplicou à educação superior do sistema federal e, logo depois, foi ampliado aos contextos de educação básica.

O ensino remoto emergencial foi interpretado por diversos autores. Tavares (2020) afirma que o EREconsiste em atividades síncronas e/ou assíncronas que não puderam ter o desejável planejamento prévio e utilizam recursos da interação a distância para atender a situações emergenciais e temporárias. Já para Edméa Santos (2020), o ERE se constitui pela utilização de aulas para cumprir a carga horária no dia e hora marcados, cabendo ao recurso assíncrono apenas o acesso a conteúdos e material de estudo da disciplina. A partir de relatos diretos de professores do ensino superior e da educação básica de diferentes partes do Brasil e, em particular, das redes públicas e particulares do Rio de Janeiro, as autoras deste artigo têm observado que, na prática, as atividades no ERE não se limitam às aulas síncronas, haja vista que muitos professores gravaram suas aulas e alunos realizaram atividades em tempos e espaços distintos. Assim, Behar (2020) destacou que o ensino remoto emergencial pressupõe o distanciamento geográfico de professores e alunos e foi adotado de forma temporária nos diferentes níveis de ensino por instituições educacionais do mundo inteiro para que as atividades escolares não fossem interrompidas.

O ensino remoto emergencial, entretanto, não foi adotado apenas em instituições educacionais, tendo sido adotado por professores e outros profissionais que atuam na educação não formal, para a melhoria e continuidade do ensino e aprendizagem. Segundo Rabello (2020), uma das formas de preparação para o ensino remoto, em qualquer contexto, consiste na participação em comunidades de prática e no acompanhamento de diferentes educadores nas redes sociais, criando uma rede de aprendizagem.

Salientamos que as práticas na educação não formal são um desafio para professores, mas pouco estudadas nas pesquisas científicas. Dentre os estudos publicados em 2020 sobre práticas pedagógicas na educação não formal durante a pandemia da COVID-19, podemos 
citar Gohn (2020), Faustino e Silva (2020), Santandes et al. (2020). Portanto, neste artigo, buscamos contribuir para o desenvolvimento de pesquisas acerca da educação não formal na pandemia, focalizando questões relacionadas à avaliação e à interação em contextos de ensino e aprendizagem on-line, nos quais o feedback assume um papel fundamental e constitutivo das práticas sociais envolvidas.

Assim, neste estudo, buscamos compreender como o feedback opera nas interações entre professora, alunos e conteúdo e na avaliação formativa e subjetiva de uma professora que atua na educação não formal durante a pandemia da COVID-19 e é uma das autoras deste trabalho. Para isso, situamos a pesquisa nas bases epistêmicas da Linguística Aplicada (LA), pois o tema da pesquisa envolve implicações sobre a vida social, como práticas sociais e discursivas dos alunos e da professora relacionadas ao ensino e aprendizagem de português. Silva (2015) atribui à LA uma vocação eminentemente pragmática, recordando que a prática linguística e social orienta qualquer trabalho na área, sendo, portanto, o foco da LA a ação social por meio da linguagem. Dessa forma, utilizamos uma abordagem qualitativa e de proximidade crítica (MOITA LOPES; FABRÍCIO, 2019) que possibilitou nossa análise e interpretação das mensagens compartilhadas, das avaliações e das respostas ao questionário.

Organizamos este trabalho em quatro seções após esta introdução. Na primeira seção, exploramos estudos sobre feedback como elemento do processo de ensino e aprendizagem on-line. Na segunda seção, apresentamos os caminhos metodológicos e o contexto em que a pesquisa se situou. Na terceira seção, discutimos os resultados, argumentando a favor do feedback como potencializador nas interações e nas avaliações dos sujeitos. Na última seção, apresentamos nossas considerações finais.

\section{Feedback no ensino e na aprendizagem on-line}

Nas últimas décadas muitos autores (e.g. BATISTA, 2020; BONNEL, 2008; CARDOSO, 2011; PAIVA, 2003; SANTOS, 2017; SIMONSON; SMALDINO; ZVACEK, 2015) têm investigado o feedback como elemento constitutivo da interação e avaliação educacional no contexto de ensino e aprendizagem on-line. Os tipos de feedback são reconhecidos pelas suas contribuições e limitações no processo de ensino e aprendizagem. Cardoso (2011) observa a incoerência em estabelecer "o melhor" dada 
V. 11 (3) 90-113 set-dez 2021

a diversidade de contextos educacionais. Assim, ressaltamos que as escolhas dos tipos de feedback a serem utilizados devem ser feitas buscando-se aqueles mais adequados a cada contexto educacional, cultural e social, ainda que seja uma tarefa árdua para o professor, tendo em vista as múltiplas classificações, objetivos e funções.

As delimitações conceituais e funcionais de feedback se evidenciam em diversos estudos, nos quais os autores propõem diversas nomenclaturas em razão das características e concepções de ensino e aprendizagem. O feedback formativo (SHUTE, 2007) e o corretivo (KIELTY, 2004) se baseiam principalmente na transmissão do saber pelo professor para a formação do aluno. Desse modo, percebemos que o professor pode ser visto como o único detentor do saber, uma vez que ele é quem comunica o conteúdo ao aluno. O feedback formativo proposto por Shute (2007) se trata de informação comunicada ao aluno para modificar o pensamento ou o comportamento dele e aumentar os conhecimentos, as habilidades e a compreensão do estudante em alguma área de conteúdo ou habilidade geral (por exemplo, resolução de problemas). Tal proposta se assemelha ao feedback corretivo caracterizado por Kielty (2004) como qualquer comentário ou sugestão verbal ou escrita que um instrutor oferece ao estudante sobre qualquer tarefa, questionário e exame com a finalidade de informar se a resposta está correta, ou ainda fornecer orientações até a alternativa correta.

Diante disso, questionamos em que medida esses tipos de feedback podem contribuir para a formação do aluno, considerando sua função predominante de transmissão de conteúdos e orientações para a resposta correta. Moran (2018) afirma que, em um sentido amplo, toda a aprendizagem é ativa em algum grau, porque exige do aprendiz e do docente formas diferentes de práticas interativas, motivadoras e avaliativas. Ainda que o feedback seja elaborado pelo professor, o aluno se constitui agente no processo de aprendizagem, conforme salienta Bonnel (2008, p. 36): "O feedback pode ser fornecido em várias ocasiões e de várias maneiras aos alunos, mas se os alunos não lerem o feedback que recebem e considerarem suas próprias respostas a ele, o processo não tem valor". Diante dessas considerações, ele cumpre seu propósito, se o aluno interage com o seu conteúdo, lendo-o, interpretando-o e colocando-o em prática.

Dessa forma, o feedback possui um caráter mais complexo que apenas um comentário, sugestão ou informação comunicada, já que pode assumir diferentes papéis a depender dos contextos educacionais, das características dos alunos, dos recursos de que o professor dispõe, 
dos objetivos do curso e das concepções pedagógicas. Aqui, adotamos uma concepção de educação freiriana. Para Paulo Freire (2000), ao fazer educação crítica, é necessário estar no mundo com os educandos, para que haja a transformação. Desse modo, reconhecendo que os aprendizes são seres sociais e históricos, buscamos colaborar para a práxis, ou seja, reflexão e ação deles sobre o mundo para transformá-lo, desconstruindo a relação opressor-oprimido.

Em muitas investigações, o feedback é representado como elemento constitutivo da avaliação e da interação. Cremilde Santos (2017) realizou uma revisão narrativa da literatura na qual constatou uma consonância entre autores, em maior ou menor grau, a respeito do feedback como recurso utilizado isoladamente ou somado a outras ferramentas de avaliação formativa e como um dos meios mais eficientes de se promover um desenvolvimento contínuo do aluno e uma melhor interação entre este e o docente.

Entendemos a necessidade de fazer algumas ponderações acerca da avaliação. Sobre a avaliação na pandemia da COVID-19, Moran (2020) sugere a adaptação da avaliação para o contexto de ensino remoto emergencial, defendendo uma avaliação que seja construída gradativamente com o desenvolvimento das aulas e das atividades reflexivas, pois o importante é que os estudantes questionem o conteúdo e expressem suas opiniões e diferentes visões. Argumenta também que o professor precisa ter flexibilidade, bom senso e humanidade, olhando afetivamente para todo esse processo e, ao mesmo tempo, encontrar alternativas de registro sobre o que está acontecendo. Sob essa ótica, a utilização de modelos planejados e previsíveis de avaliação pode colaborar com a avaliação remota, entretanto, devem ser flexibilizados, considerando os contextos dos alunos e do professor. Desse modo, levantamos algumas especificidades das avaliações subjetivas e formativas consideradas nesse processo. $O$ ato de avaliar, segundo Freitas et al. (2009), ocorre ao longo de todo processo de ensino e aprendizagem, consciente ou inconscientemente, pois orienta nossa atuação na escola e nas salas de aula atuais. Sob esse viés, nós, professores, pensamos em avaliação como uma forma de melhorar o ensino e, consequentemente, a aprendizagem dos alunos.

A avaliação se destina à inclusão, à melhoria do ciclo de vida do aprendiz, à obtenção do melhor resultado possível, ao acolhimento da realidade como ela é, seja satisfatória ou insatisfatória, agradável ou desagradável (HOFFMANN, 1993). Segundo Simonson, Smaldino e Zvacek (2015), a melhor evidência de aprendizagem se encontra no 
V. 11 (3) 90-113 set-dez 2021 comportamento do aprendiz, e a avaliação funciona como uma atividade motivacional, a fim de manter o aprendiz na responsabilidade de ter e colocar em prática um conjunto de conhecimentos ou habilidades. Para os autores, o propósito mais importante para avaliar os ganhos de aprendizagem é fornecer feedback aos alunos e instrutores. Assim, os alunos ganham um senso de controle e podem assumir maior responsabilidade por seu próprio aprendizado se souberem seu desempenho em relação ao conjunto de critérios. Por certo que ele não ocorre apenas como elemento da avaliação educacional, mas no processo educacional como um todo.

Estudos realizados sobre a interação entre os pares têm demonstrado a multimodalidade do feedback. Anderson (2003) entende interação como um conceito multifacetado em todos os contextos educacionais, no entanto, considera que essa ocorre quando sujeitos e objetos se influenciam mutuamente em contextos síncronos ou assíncronos. O feedback pode ser entregue através de texto, áudio, vídeo, realidade virtual ou uma combinação desses gêneros de comunicação. Conforme Paiva (2003), nas interações on-line, ele pode funcionar como avaliação do processo de aprendizagem ou como mecanismo que impulsiona, inibe ou calibra a interação entre sujeitos inseridos ou não no ambiente de aprendizagem ou computador. A autora postula dois tipos básicos de feedback: avaliativo e interacional.

O feedback avaliativo informa sobre o desempenho educacional do aluno ou do professor e o interacional registra reações ao comportamento interacional do aluno e do professor (PAIVA, 2003, p. 219). Assim, ele tem um papel relevante e abrangente nas relações humanas, seja nas conversas espontâneas ou nas interações educacionais. Cardoso (2011) analisou mensagens dos fóruns de um curso on-line e identificou "dois tipos de feedback aluno-aluno na categoria motivacional/interacional e dez tipos na categoria informativo/ avaliativo" (CARDOSO, 2011, p. 165), que contribuem para motivação e compartilhamento de conhecimentos entre os pares.

Diante dessas considerações, concluímos que o feedback faz parte da práxis dos sujeitos e funciona como elemento da interação entre professores, alunos e conteúdos. Os sujeitos-praticantes consideram as condições de produção, ou seja, o interlocutor, o conteúdo, o objetivo, a função para elaboração. Constituindo-se como elemento da prática avaliativa, colabora na mediação de conhecimentos e habilidades em diversos contextos de educação. 


\section{Metodologia e contexto de pesquisa}

Adotamos, nesta pesquisa, uma abordagem qualitativa baseada em alguns princípios da proximidade crítica elencados por Moita Lopes e Fabrício (2019), considerando a premissa de que é impossível ignorar a visão dos participantes, pois essa determina o mundo social. Consideramos, assim, a pluralidade de enunciados da professora e dos alunos participantes desta pesquisa em ação no mundo social, estabelecendo a proximidade entre sujeito e objeto de pesquisa, e a implicação das pesquisadoras com o processo de produção de conhecimento. Buscamos interpretar os múltiplos significados que constituem as realidades sociais, pautando-nos na abordagem qualitativa.

Conforme já indicado, nosso objetivo de pesquisa consiste em compreender como o feedback opera nas interações entre professora, alunos e conteúdo e na avaliação formativa e subjetiva da professora, uma das autoras deste artigo, que atua na educação não formal durante a pandemia da COVID-19.

Alinhamo-nos a uma agenda ética de investigação em LA que envolve crucialmente

um processo de renarração ou redescrição da vida social como se apresenta que se relaciona à necessidade de compreendêla. Esse processo se faz essencial para que o linguista aplicado possa situar seu trabalho no mundo (MOITA LOPES, 2006, p. 90).

Em março de 2020, tal professora de língua portuguesa na educação não formal, residente na baixada fluminense, precisou adaptar o modo de dar aulas e, principalmente, de avaliar as produções textuais dos alunos, devido à pandemia da COVID-19. Inicialmente, as aulas de produção textual para concursos públicos, ministradas de forma voluntária e gratuita, seriam presenciais para alunos da baixada fluminense do estado do Rio de Janeiro. Contudo, pela necessidade do isolamento e distanciamento social, as aulas foram realizadas pelo aplicativo de mensagens instantâneas WhatsApp e as correções das produções textuais foram feitas com uso do software Microsoft Word e também do WhatsApp. Os seis alunos que fizeram o curso já tinham concluído o ensino médio ou a graduação e não eram apenas os residentes da baixada fluminense, mas de outras regiões empobrecidas do país. 
V. 11 (3) 90-113 set-dez 2021

Como mestranda e bolsista do Programa Interdisciplinar de Pós-Graduação em Linguística Aplicada da Universidade Federal do Rio de Janeiro, a professora cursou a disciplina Discurso e Novas Tecnologias, ministrada de forma remota no primeiro semestre de 2020. A participação ativa na comunidade solícita, empática e solidária, que se formou na referida disciplina, possibilitou à professora aprender conhecimentos acerca da avaliação, tipos de interação e feedback do ensino a distância e inseri-los em sua prática pedagógica no ensino remoto.

Em meio às dificuldades com as conexões de internet, a professora optou por avaliações e comunicações realizadas em tempo e espaço diversos. Os alunos poderiam enviar sua produção textual a qualquer momento. Prosseguir com os estudos na pandemia não é uma tarefa fácil, muitos desanimam pelo sofrimento humano causado pela discriminação racial e social, pelo medo caótico e pela morte sem fronteiras. Boaventura Santos (2020, p. 15) afirma que "qualquer quarentena é sempre discriminatória, mas difícil para uns grupos sociais".

As interações entre a professora, os alunos e o conteúdo ocorriam em diversos momentos da produção textual por WhatsApp, por se tratar de um aplicativo que consumia menos dados de internet e de fácil acesso aos smartphones. A professora realizava a avaliação subjetiva (SIMONSON; SMALDINO; ZVACEK, 2015), que requeria julgamento humano para pontuação e incluía tarefas como produção textual. Assim, para facilitar e avaliar os ganhos de aprendizagem, a avaliação continha rubricas baseadas nos editais dos concursos públicos que orientavam o feedback da professora. De acordo com Simonson, Smaldino e Zvacek (2015), uma rubrica é uma estrutura descritiva para orientar a avaliação de tarefas complexas ou aquelas que requerem julgamento individual. Às vezes, uma rubrica consiste em uma simples lista de características ou descrições, alinhadas com níveis de qualidade, tais como destacado, bom, justo e inaceitável, ou valores de pontos dados para cada nível. A seguir, mostramos um exemplo de avaliação de prova discursiva a partir de rubricas elaboradas pela professora com base em um edital de concurso público do Estado do Rio de Janeiro. 
Quadro 1- Exemplo de avaliação de prova discursiva orientada por rubricas

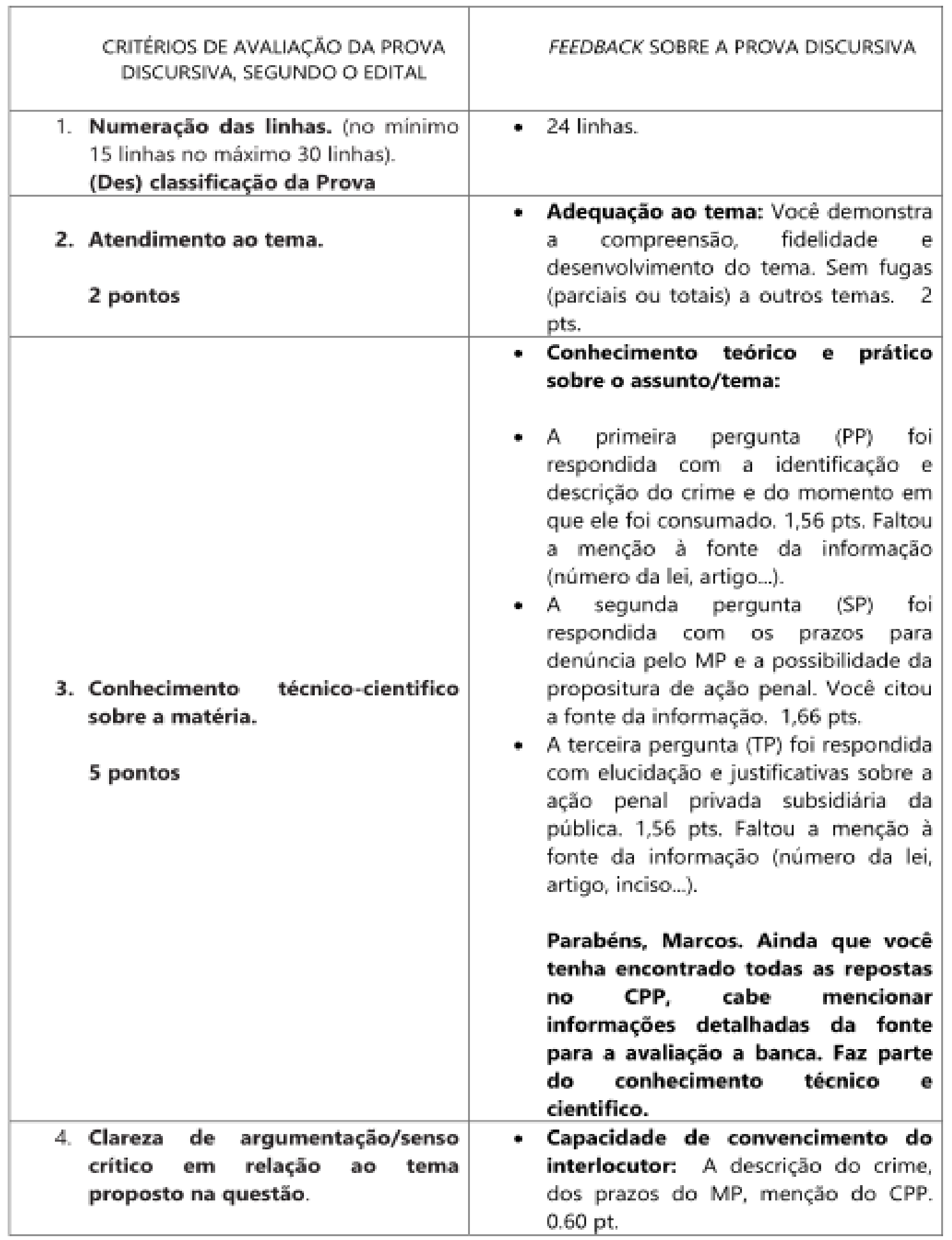

Fonte: Autoras (2020).

A fim de compreender como o feedback integra a interação e avaliação no contexto investigado, analisamos e interpretamos as mensagens trocadas pela professora e os alunos no aplicativo, como também a avaliação das produções textuais dos alunos e as respostas do questionário no Google Forms aplicado pela professora após o final do curso. 
v. 11 (3) 90-113 set-dez 2021

\section{Discussão dos resultados: feedback no ensino remoto emergencial}

Apresentamos, em duas subseções, como o feedback integra e fomenta as interações entre professora, alunos e conteúdo e a avaliação nas aulas de português para concursos ministradas pela professora, uma das autoras deste artigo, durante a pandemia da COVID-19. Na primeira subseção, apresentamos como o feedback professora-aluno/alunoprofessora se constitui nas interações entre os sujeitos e conteúdos a partir da análise de troca de mensagens no aplicativo WhatsApp. Na segunda seção, abordamos como o feedback professora-aluno/aluno-professora se caracteriza na avaliação subjetiva da professora baseada em rubricas e na avaliação feita pelos próprios alunos. Em vista da limitação espacial deste artigo, selecionamos os dados mais pertinentes, ilustrando com exemplos.

\section{Feedback: Potencializador das interações no ensino remoto emergencial}

Por meio da análise e interpretação das mensagens no aplicativo WhatsApp, identificamos que o feedback pode potencializar as interações entre professora, alunos e conteúdos. Da mesma forma, Batista (2020) observou que nas aulas-live de uma professora Youtuber, houve predominância do feedback imediato e interacional, tanto de professor-aluno quanto de aluno-aluno com a função de movimentar toda a interação nas aulas-live e garantir o engajamento dos alunos: "Os alunos enviavam suas contribuições e suas dúvidas e esperam um retorno do professor e dos colegas" (BATISTA, 2020, p. 69).

Nesta pesquisa, constatamos que o feedback professoraaluno, dado através de mensagens pelo aplicativo WhatsApp, consiste na sugestão de conteúdos, no esclarecimento de dúvidas e na apresentação/ discussão sobre a avaliação. Outrossim, o feedback aluno-professora, dado a partir do feedback da professora, compreende a apresentação de conhecimentos prévios, formulação de dúvidas/questionamentos, elaboração de resumo e paráfrase sobre a avaliação da professora.

No exemplo a seguir, o feedback dado pela professora sugere hyperlink e arquivos de textos sobre a importância da música no contexto social e político para o aluno. A professora ainda explica que esses textos colaboram para a ampliação do repertório sociocultural dele, fundamental para o enriquecimento dos conteúdos da produção escrita do aluno: "Nada [...]. Vai lendo com calma ao longo da semana. Esses textos te darão muitas ideias". 


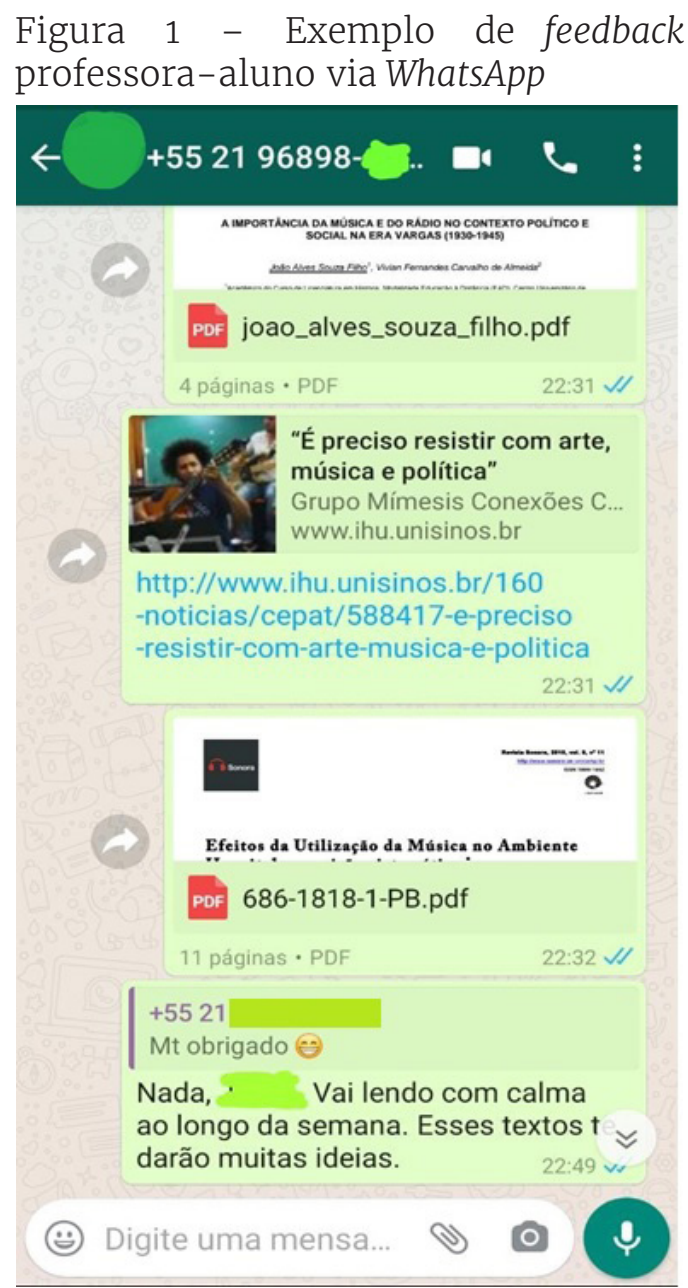

Fonte: Autoras (2020).

A sugestão de hyperlinks também está presente no feedback dado pela professora na captura de tela a seguir. Nesse exemplo, ela sugere sites que apresentam diversos temas de redação ligados à pandemia para ampliação do repertório sociocultural da aluna. 


\section{11 (3)}

90-113

set-dez

2021
Figura 2 - Exemplo de feedback professora-aluno via WhatsApp

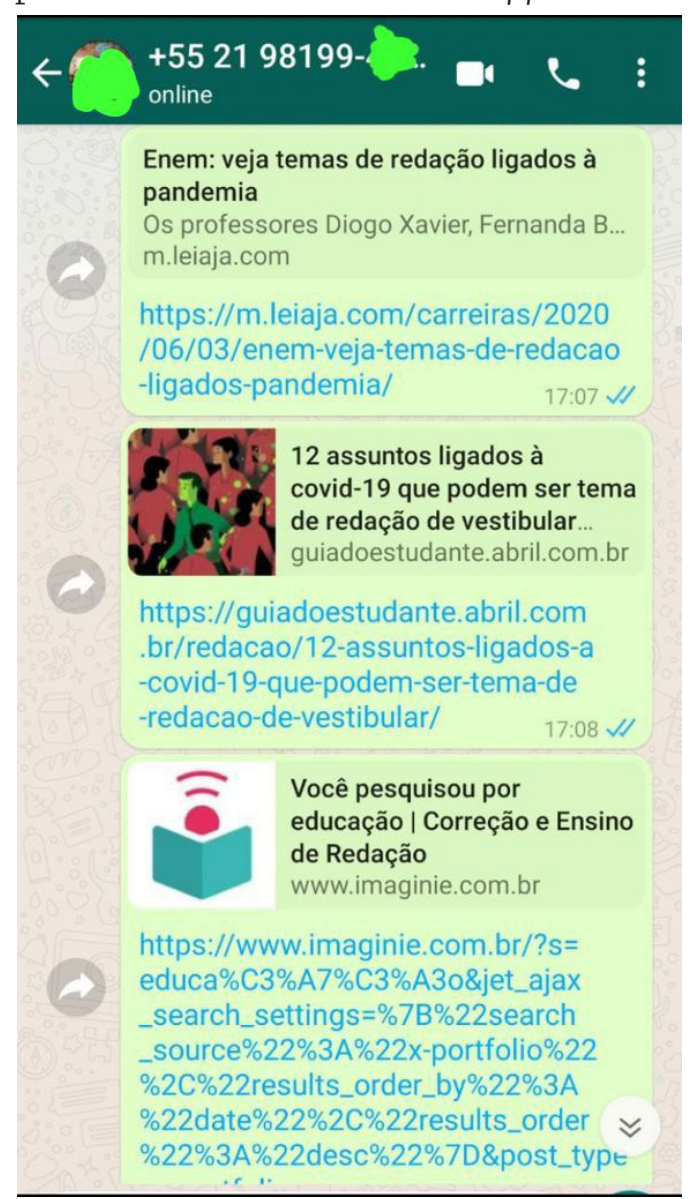

Fonte: Autoras (2020).

Na próxima captura de tela, a aluna interage com a professora para esclarecer dúvidas, expondo suas hipóteses e questões sobre o feedback da prova discursiva dado pela professora por mensagens de voz, e finaliza avaliando seu próprio desempenho ("Escrevi rápido e acabou passando esse erro. Tenho que ter atenção. Citei o Eca de forma errada."). Cumpre destacar que o uso de mensagens de voz nesse exemplo se soma ao uso de mensagens de texto, links e arquivos presentes em outros exemplos aqui apresentados para ilustrar a variedade de formas de feedback proporcionada pela interação por WhatsApp. Note-se ainda que o aplicativo permite que cada resposta seja dada em relação a uma mensagem anterior específica, dinamizando e organizando o diálogo. Na parte inferior da imagem a seguir, é possível, inclusive, ver que a professora começa a responder à primeira mensagem da aluna. 
Figura 3 - Feedback aluno-professora via WhatsApp

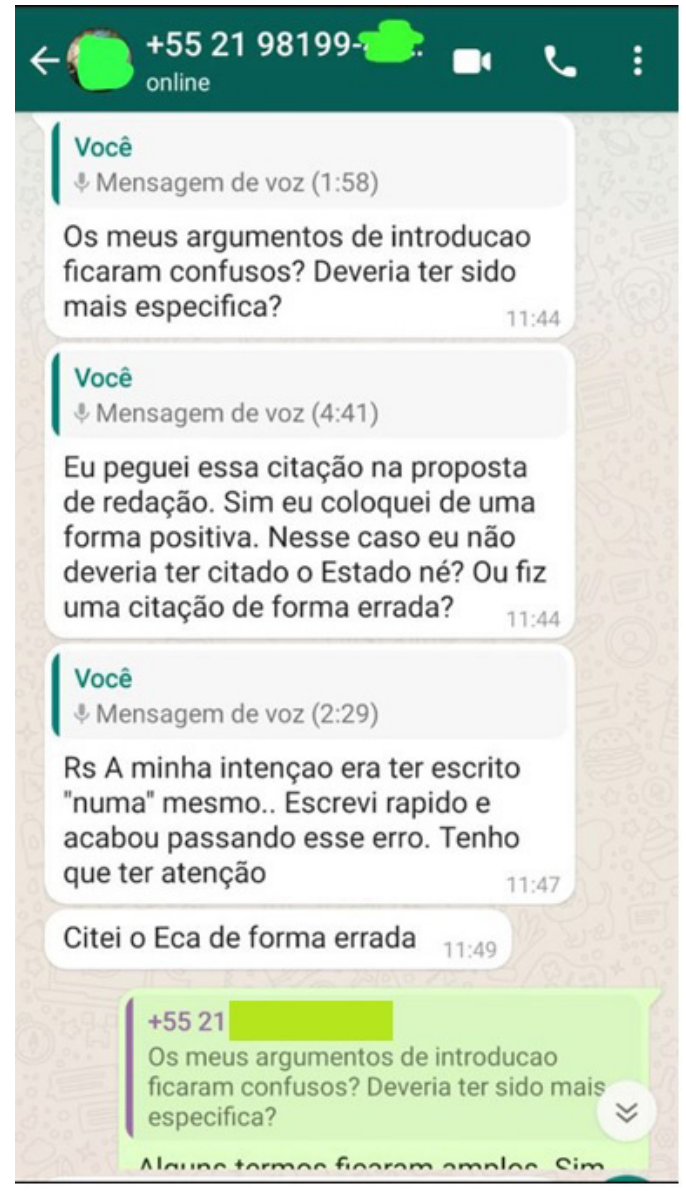

Fonte: Autoras (2020).

A seguir, o feedback elaborado pela aluna resume a avaliação enviada a ela pela professora e conclui seu entendimento acerca da sua própria escrita: "Boa noite. Nas últimas duas redações meus erros estavam nas ausências de fontes. Nestas duas recebidas, os erros estão na concordância verbal. Tenho que prestar mais atenção nisso [...]". A partir dessa autoavaliação, a interação prossegue com a professora dando à aluna uma orientação para o momento da prova: rever o texto antes de entregá-lo. 
V. $11(3)$

90-113

set-dez

2021
Figura 4 - Feedback aluno-professora via WhatsApp

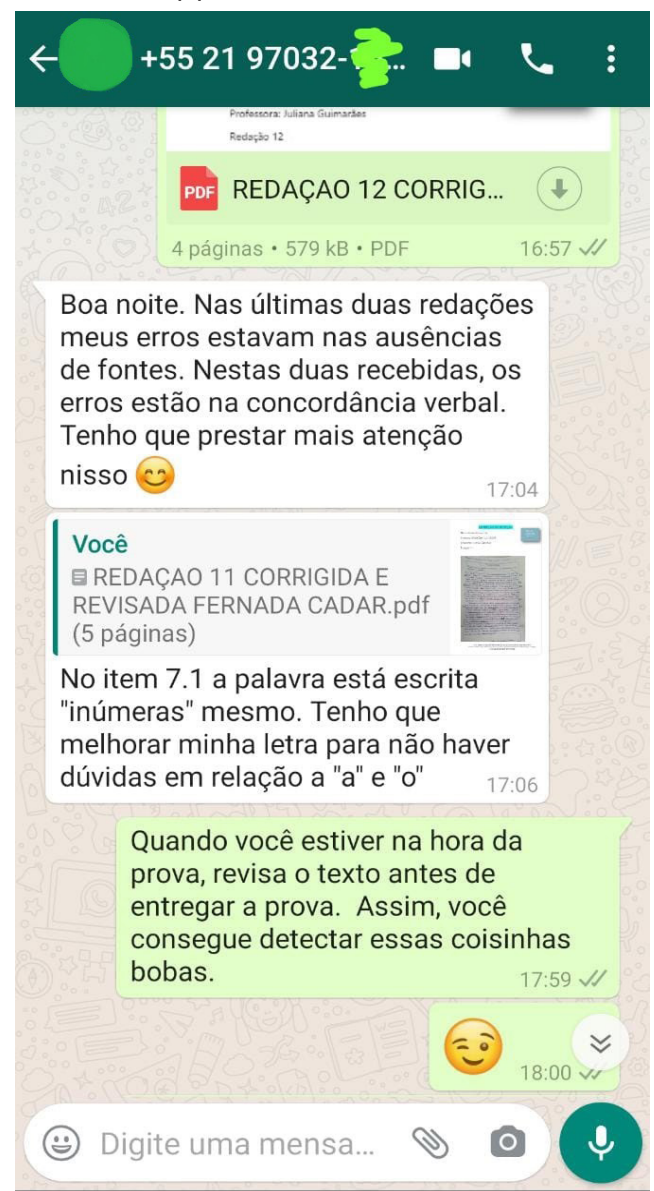

Fonte: Autoras (2020).

Diante disso, entendemos que essa interação entre professor e aluno colabora para a formação de conhecimentos e habilidades sociocomunicativas e linguísticas. Conforme constatado por Leffa (2005), o aluno interage com o professor principalmente para esclarecer dúvidas sobre o conteúdo, não apenas para responder perguntas feitas pelo professor. Além disso, como já afirmado por Archer, Crispim e Cruz (2016, p. 479), o feedback é utilizado como um meio formativo que possibilita a identificação pelo estudante de quais características de seu desempenho necessitam ser melhoradas e/ou mantidas.

\section{Feedback: fomentador das avaliações no ensino remoto emergencial}

Por meio da análise das avaliações das produções textuais feitas com uso do software Microsoft Word e do questionário aplicado pela professora, verificamos que o feedback pode fomentar as avaliações da professora e dos alunos, contribuindo para a formação de ambos. 
O feedback avaliativo produzido pela professora oferece aos alunos os seguintes itens: reflexão e questionamento acerca do uso da linguagem e de questões da vida em sociedade que levam a ética ao centro da discussão e do exercício da cidadania; resolução de problemas socioculturais e socio-históricos; percepção do progresso individual; e elucidações sobre a composição de determinado gênero textual e sobre regras linguísticas. Fuzer e Weber (2012) constataram a contribuição do feedback para o processo de crescimento cognitivo do estudante quando estão claros

os procedimentos que norteiam essa etapa no trabalho de escrita; o que se espera de produção no contexto de determinada tarefa; o estabelecimento de critérios e a forma pela qual o feedback será dado (o significado de cada questão ou resposta ao texto do aluno) (FUZER; WEBER, 2012, p. 39).

No exemplo a seguir, evidenciamos o feedback avaliativo produzido pela professora sobre a composição do gênero textual redação dissertativa-argumentativa. Marcuschi (2002, p. 155) afirma que os gêneros textuais são

textos que encontramos na nossa vida e que apresentam padrões sociocomunicativos característicos definidos por composições funcionais, objetivos enunciativos e estilos concretamente realizados na integração de forças históricas, sociais, institucionais e técnicas.

Assim, com a finalidade de contribuir para o processo de reescrita do gênero pelo aluno, a professora avalia a composição e estilo do gênero textual produzido pelo aluno:

Você inicia o parágrafo, com uma frase geral sobre o contexto atual. Critério cumprido. Em seguida, apresenta as suas duas teses, a saber: as trilhas sonoras ajudam na diminuição dos níveis de ansiedade e depressões, bem como no entretenimento. $[\ldots]$ 
V. 11 (3) 90-113 set-dez 2021
Quadro 2 - Exemplo de feedback professora-aluno com avaliação baseada na rubrica "Tipologia e gênero textual"

\section{TIPOLOGIA E GÊNERO TEXTUAL}

1.1-Você inicia o parágrafo, com uma frase geral sobre o contexto atual. CC Em seguida, apresenta as suas duas teses, a saber: as trilhas sonoras ajudam na diminuição dos níveis de ansiedade e depressões, bem como no entretenimento. CC

O parágrafo está bem estruturado.

1.2- No primeiro parágrafo do desenvolvimento, apresenta a ideia central ao longo do parágrafo, ( $\mathrm{O}$ auxílio da música no combate as doenças de ansiedade e depressão durante a quarentena.) que corresponde a tese apresentada na introdução. CC Além disso, você a desenvolve com uma pesquisa, bem como, com autoria que se relaciona com a tese. CC.

1.3- No segundo parágrafo do desenvolvimento, expõe a sua ideia central (O auxílio das apresentações musicais no entretenimento durante a pandemia) que contempla a sua tese no parágrafo da introdução. $\mathrm{CC}$ $\mathrm{E}$ também, você a fundamenta com outra pesquisa e autoria. CC.

Nos dois parágrafos do desenvolvimento, você fez uma introdução = sua ideia central, um desenvolvimento $=$ argumentos/ exemplos/autoria, e uma conclusão = utilize um conector ou locução conclusiva e uma frase conclusiva. CC

1.4- No parágrafo da conclusão, houve a retomada do que foi dito (com a locução conjuntiva conclusiva-Portanto), principalmente, das teses desenvolvidas nos parágrafos anteriores. Com proposta de melhoria para as duas teses. CC

Finalização com uma frase de efeito que torna sua tese mais coerente $\mathrm{CC}$

Fonte: Autoras (2020).

No exemplo a seguir, após oferecer feedback detalhado sobre a redação da aluna com base em rubricas, a professora destaca uma questão sobre a composição do gênero textual, tendo em vista o edital de um concurso, e faz uma recomendação que remete à redação anterior da aluna ("[...] tente fazer como a prova anterior e argumente na conclusão"), o que acaba por destacar a importância de se estar atento ao próprio processo de aprendizagem da escrita. 


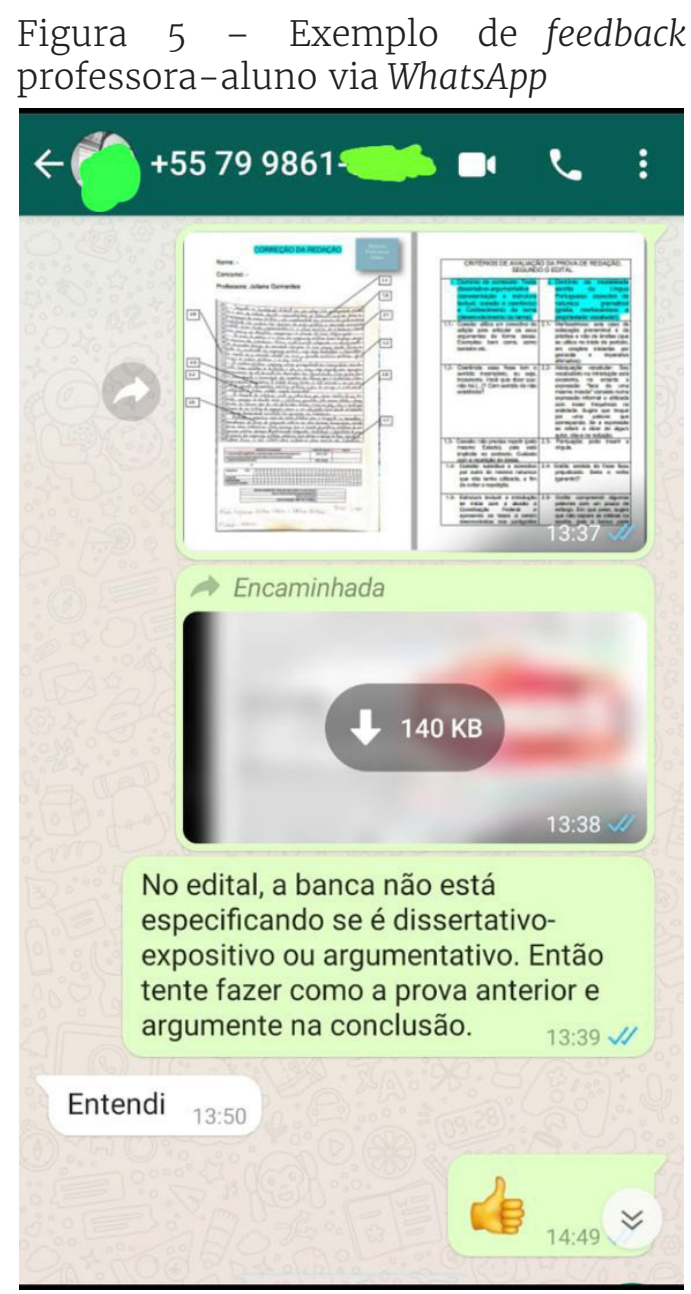

Fonte: Autoras (2020).

Já no trecho de interação por WhatsApp reproduzido na imagem a seguir, a partir do feedback avaliativo que recebeu previamente da professora, o aluno busca esclarecer os critérios de avaliação da redação ("falta de repertório cultural, como assim? Para uma redação completa é de fato necessário?") e elucidar sua dúvida sobre a estrutura do parágrafo ("não entendi a parte do não concluiu o parágrafo"). Em outras palavras, o feedback avaliativo da professora levou o aluno a se interessar pelo que é esperado dele no contexto de produção de uma redação dissertativa. Por sua vez, a partir dos questionamentos do aluno, a professora confirma o repertório cultural como importante critério de avaliação da produção escrita de acordo com o edital de um concurso e explicita a composição esperada do parágrafo, que inclui introdução, desenvolvimento e conclusão. 
V. $11(3)$ 90-113 set-dez 2021
Figura 6 - Exemplo de feedback alunoprofessora e professora-aluno via

WhatsApp

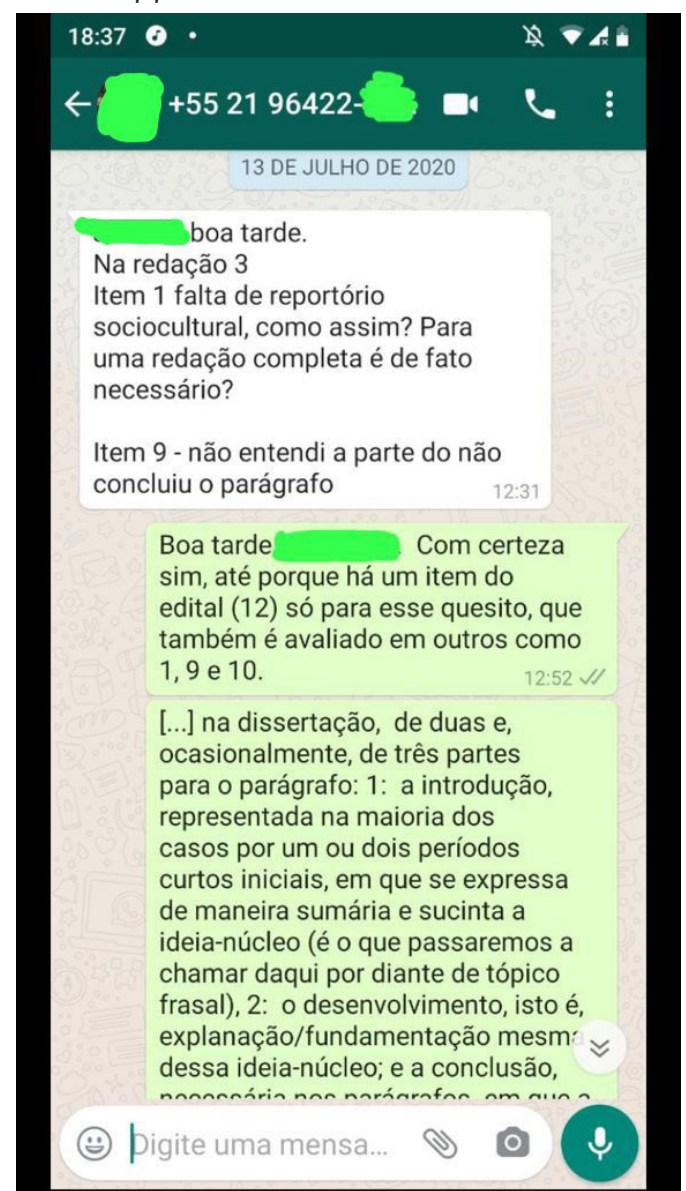

Fonte: Autoras (2020).

O feedback dos alunos sobre o próprio processo de avaliação e reescrita de seus textos fornece à professora as opiniões/sugestões dos alunos sobre a experiência no ensino remoto. Ao serem perguntados, através de questionário feito por Google Forms, sobre o que a experiência de (re)elaboração textual significou para eles, dos cinco alunos que responderam ao questionário, três indicaram o desenvolvimento de competências de leitura e escrita, um destacou a interação nas plataformas digitais sobre redação, dois apreciaram a superação de expectativas com a revisão/correção e quatro alunos consideraram a experiência como um diferencial nos seus estudos sobre redação.

Diante do exposto, defendemos que o feedback fomenta a avaliação formativa do ensino remoto emergencial. Para Cremilde Santos (2017, p. 22), o aluno que recebe feedback do docente em variados momentos do processo de aprendizagem adquire autonomia para regular e avaliar seu próprio desenvolvimento cognitivo e, ao mesmo tempo, constrói uma relação interativa de parceria com o professor 
na busca de estratégias para o alcance de sua capacidade máxima de aprendizado. Desse modo, a avaliação fornecida pela professora e pelos alunos possibilita a contribuição de todos para o processo de ensino e aprendizagem. Ainda que, conforme apontado por Dellagnelo (1998, p. 66), o feedback do professor não resolva todos os problemas encontrados nos textos dos alunos-escritores, ele pode ajudá-los a desenvolver sua capacidade de produção textual.

\section{Considerações finais}

Concluímos que o feedback é constitutivo e potencializador das interações síncronas e assíncronas e da avaliação na educação não formal durante o ensino remoto emergencial. Com base nos dados, compreendemos que o feedback interacional se mostra pertinente no diálogo entre a professora e os alunos, baseado na confiança e no respeito. O feedback avaliativo se apresenta relevante para (re)construção de conhecimentos e habilidades dos alunos sobre temas, características sociocomunicativas, culturais, textuais, questões de vida em sociedade que levam a ética ao centro da reflexão e do exercício da cidadania.

Grasel e Pinto (2020) e Tavares (2020) salientam que diversas contribuições da Educação a Distância poderiam servir em tempos de crise sanitária: feedback na comunicação e o uso de ferramentas digitais como forma de interação e não como repositório de conteúdo. Prata et al. (2020) constatam que a vivência de educação não formal contribui para a aquisição de saberes e para o planejamento de ensino formal no futuro retorno após o término da pandemia da COVID-19.

Como a educação não formal no senso comum e na mídia, e até nos estudos e publicações sobre ensino remoto emergencial, assume um lugar de desprestígio, destacamos a necessidade de políticas públicas voltadas para a valorização e o aperfeiçoamento dos professores que atuam nesse contexto e a preocupação de pesquisadores com investigações nesse campo.

Esperamos que este trabalho contribua para que professores da educação não formal possam (res)significar suas práticas docentes, tendo em vista o uso das tecnologias de comunicação e informação, a elaboração e recebimento de feedback na interação e na avaliação com seus alunos, caminhando para adoção do ensino híbrido ou blended learning (TAVARES, 2020) nas metodologias e propostas educacionais, conforme Moran (2015) já defendia para educação formal: 
V. $11(3)$

90-113

set-dez

2021
Em educação - em um período de tantas mudanças e incertezas - não devemos ser xiitas e defender um único modelo, proposta, caminho. Trabalhar com modelos flexíveis com desafios, com projetos reais, com jogos e com informação contextualizada, equilibrando colaboração com a personalização é o caminho mais significativo hoje, mas pode ser planejado e desenvolvido de várias formas e em contextos diferentes (MORAN, 2015, p.25).

Finalmente, apontamos algumas questões não investigadas neste estudo que podem ser contempladas em futuras pesquisas: Como o feedback aluno-aluno se constitui na interação e avaliação entre os pares na educação não formal? Que outras estratégias e tecnologias digitais da informação e comunicação podem ser utilizadas para proporcionar feedback interacional e avaliativo de qualidade? Quais são os impactos do ensino remoto emergencial para a educação não formal?

\section{Referências}

ANDERSON, T. Modes of Interaction in Distance Education: Recent Developments and Research Questions. In: MOORE, M.; ANDERSON, W. Handbook of Distance Education. Laurence Erlbaum Association, New Jersey, 2003.

ARCHER, A. B.; CRISPIM, A. C.; CRUZ, R. M. Avaliação e feedback de desempenho de estudantes na educação a distância. Avances en psicología latinoamericana, [s. l.], v. 34, n. 3, p. 473-485, 2016.

BATISTA, F. F. Youtube como ambiente virtual de ensino e aprendizagem: características de aulas-live de espanhol. 2020. 89 f. Dissertação (Mestrado em Linguística) - Centro de Educação e Ciências Humanas, Universidade Federal de São Carlos, São Carlos, 2020.

BEHAR, P. A. O ensino remoto emergencial e a educação à distância. Jornal da Universidade, Porto Alegre: UFRGS, v. 14, n. 8, 2020. Disponível em: https://www.ufrgs.br/jornal/o-ensino-remoto-emergencial-e-a-educacaoa-distancia/?fbclid=IWARoePPmrjnaxcGUKj5Z3lP8vnHhuzhbzElSVaRgh_F3U3ACRlzH-wqiu-A. Acesso em: 20 out. 2020.

BONNEL, W. Improving feedback to students in online courses. Nursing Education Perspectives, Philadelphia, v. 29, n. 5, p. 290-294, 2008.

BRASIL. Ministério da Educação. Portaria n. 343, de 17 de março de 2020. Brasília, DF: Ministério da Educação, 2020. 39 p.

CARDOSO, A. C. S. Feedbackaluno-aluno em um curso de extensão universitária on-line. 2011. 214 f. Dissertação (Mestrado em Linguística Aplicada) - Centro de Letras e Artes, Universidade Federal do Rio de Janeiro, Rio de Janeiro, 2011.

DELLAGNELO, A. C. K. A influência do "feedback" do professor nas revisões de seus alunos. Revista Linguagem \& Ensino, Pelotas: UFPel, v. 1, n. 2, p. 59-70, 1998. 
FABRÍCIO, B. Linguística Aplicada como espaço de desaprendizagem: redescrições em curso. In: MOITA LOPES, L. P. (org.). Por uma Linguística Aplicada Indisciplinar. São Paulo: Parábola, 2006, p. 45-65.

FAUSTINO, L. S.; SILVA, T. Educadores frenteà pandemia: dilemas e intervenções alternativas para coordenadores e docentes. Boletim de Conjuntura (BOCA), Boa Vista, v. 3, n. 7, p. 53-64, 2020.

FREIRE, P. Pedagogia da indignação: cartas pedagógicas e outros escritos. São Paulo: UNESP, 2000.

FREITAS, L. C.; SORDI, M. R. L.; FREITAS, H. C. L.; MALAVASI, M. M. S. Avaliação educacional: caminhando pela contramão. Petrópolis: Vozes, 2009. 88p.

FUZER, C.; WEBER, T. Um passo de cada vez. A (re) escrita em resposta a "feedbacks" no processo ensino-aprendizagem de produção textual. Cadernos de Linguagem e Sociedade. Brasília, n. 13, p. 36-60, 2012.

GOHN, M. G. Educação não formal: Direitos e aprendizagens dos cidadãos (ãs) em tempos do coronavírus. Humanidades \& Inovação, Palmas, v. 7, n. 7, p. 9-20, 2020.

GRASEL, P.; PINTO, A. Contribuições da EAD em tempos de crise. In: SEMINÁRIO NACIONAL DE INCLUSÃO DIGITAL, 6., 2020, Passo Fundo. Anais [...]. Passo Fundo: UFP, 2020.

HOFFMANN, J. Avaliação mediadora: uma prática em construção da préescola à universidade. Porto Alegre: Mediação, 1993.

KIELTY, L. Feedback in Distance Learning: Do students perceptions of corrective feedback affect retention in Distance Learning? Theses and Dissertations. Paper 1114. University of South Florida, 2004. Disponível em: http://scholarcommons.usf.edu/etd/1114. Acesso em: 5 ago. 2020.

LEFFA, V. J. Interação virtual versus interação face a face: o jogo de presenças e ausências. Trabalho apresentado no Congresso Internacional de Linguagem e Interação, Anais [...]. São Leopoldo: Unisinos, 2005.

MARCUSCHI, L. A. Gêneros textuais: definição e funcionalidade. In: DIONÍSIO, A.P; MACHADO, A. R.; BEZERRA, M. A. (orgs.). Gêneros Textuais e Ensino. Rio de Janeiro: Editora Lucerna, 2002.

MOITA LOPES, L. P. Linguística Aplicada evida contemporânea: problematização dos construtos que têm orientado a pesquisa. In: MOITA LOPES, L. P. (org.). Por uma Linguística Aplicada Indisciplinar. São Paulo: Parábola, 2006, p. 85-107.

MOITA LOPES, L. P.; FABRÍCIO, B. F. Por uma 'proximidade crítica' nos estudos em Linguística Aplicada. Calidoscópio, [s. l.], v. 17, n. 4, p. 711-723, 9 dez. 2019.

MORAN, J. Mudando a educação com metodologias ativas. Coleção mídias contemporâneas. Convergências midiáticas, educação e cidadania: aproximações jovens, Ponta Grossa, v. 2, n. 1, p. 15-33, 2015. 
V. $11(3)$ 90-113 set-dez 2021

112

MORAN, J. Metodologias ativas para uma aprendizagem mais profunda. In: BACICH, L.; MORAN, J. (org.). Metodologias ativas para uma educação inovadora: uma abordagem teórico-prática. Porto Alegre: Penso, p. 2-25, 2018.

MORAN, J. Adaptar processos avaliativos durante aulas remotas ajuda a engajar estudantes. In: VIVESCER JORNADAS DE APRENDIZAGEM, 1., 2020, Amazonas. Anais [...]. Amazonas: Vivescer, 2020.

PAIVA, V. L. M. O. Feedback em Ambiente Virtual. In: LEFFA, V. (org.). Interação na aprendizagem das línguas. Pelotas: EDUCAT, 2003. Disponível em: www. veramenezes.com/feedback.htm. Acesso em: 23 set. 2020.

PRATA, J. A; MELLO, A. S.; COSTA E SILVA, F. V.; FARIA; M. G. A. Mediações pedagógicas de ensino não formal da enfermagem durante a pandemia de COVID-19. Revista Brasileira de Enfermagem, Brasília, v. 73, n. 2, p. 1-5, 2020.

RABELLO, C. R. L. Como me preparar para o Ensino Remoto? In: RABELLO, C. R. L. Tecnologias Digitais e Ensino de Línguas. 7 ago. 2020. Disponível em: http://cintiarabello.com.br/2020/08/07/como-me-preparar-para-o-ensinoremoto/. Acesso em: 21 out. 2020.

SANTANDES, R.; VIDOTTI, A. P.; MARTINS, I. P.; PERLES, J. V. C. M.; FELTRIN, B. C. Covid-19 em tempos de isolamento: Educação não formal e jogos para informar e sensibilizar. Arquivos do Mudi, Curitiba, v. 24, n. 2, p. 127-139, 2020.

SANTOS, B. S. A cruel pedagogia do vírus. São Paulo: Boitempo Editorial, 2020.

SANTOS, C. M. A contribuição do feedback no processo de avaliação formativa: uma revisão da literatura. 2017. 25 f. Monografia (Especialização em Acompanhamento, Monitoramento e Avaliação na Educação em Saúde Coletiva) - Escola de Enfermagem, Universidade Federal do Rio Grande do Sul, Porto Alegre, 2017.

SANTOS, E. EAD, palavra proibida. Educação online, pouca gente sabe o que é. Ensino remoto, o que temos. Revista Docência e Cibercultura, ago.de 2020, online. Disponível em: https://www.e-publicacoes.uerj.br/index.php/re-doc/ announcement/view/1119. Acesso em: 20 set. 2020.

SHUTE, V. J. Focus on formative feedback. ETS Research \& Development. Princeton, NJ, March 2007. Disponível em: www.ets.org/Media/Research/pdf/ RR-07-11.pdf. Acesso em: 23 jul. 2020.

SILVA, D. N. 'A propósito de Linguística Aplicada' 30 anos depois: quatro truísmos e quatro desafios. D.E.L.T.A., São Paulo, v.31, n.4 esp., 2015, p.349$376,2015$.

SIMONSON, M.; SMALDINO, S.; ZVACEK, S. Assessment for Distance Education. In: SIMONSON, M.; SMALDINO, S.; ZVACEK, S. Teaching and Learning at a distance. Foundations of Distance Education. Charlotte, North Carolina, 2015. E-book.

TAVARES, K. C. A.; RABELLO, C. R. L.; FRANCO, C. P.; WhatsApp na formação continuada de professores: mais que um aplicativo de mensagens instantâneas? In: SCHAFER, G. M.; ROZENFELD, C. C. F. (orgs.). Ensino de línguas e tecnologias móveis: políticas públicas, conceitos, pesquisas e práticas em foco. São Paulo: Edições Hipótese, 2018. 
TAVARES, K. C. A. Ferramentas para atividades remotas em Pós-graduação. Conferência proferida no I WebFórum de Ensino Remoto Emergencial em Tempos de Pandemia, Faculdade de Letras da Universidade Federal do Rio de Janeiro, 2020. 18 eslaides.

TRILLA. J. A educação não-formal. In: TRILLA, J.; GHANEM, E.; ARANTES, V. A. (org.). Educação Formal e Não formal: Pontos e contrapontos. São Paulo: Summus, 2008. 